\title{
El asentamiento de Puente Melchor (Puerto Real, CÁDIZ): INTEGRACIÓN DE FOTOGRAMETRÍA Y TELEDETECCIÓN AÉREA Y SUS VISUALIZACIONES CON RESULTADOS ARQUEOLÓGICOS EN UN YACIMIENTO DE CARÁCTER LITORAL
}

\author{
The Puente Melchor settlement (Puerto Real, \\ CÁDIZ): INTEGRATION OF AERIAL PHOTOGRAMMETRY AND \\ REMOTE SENSING AND THEIR VISUALIZATIONS WITH \\ ARCHAEOLOGICAL RESULTS IN A COASTAL SITE
}

\author{
ISABEL RONDÁN SEVILLA \\ isabel.rondan@uca.es \\ Universidad de Cádiz ${ }^{1}$ \\ [RECIBIDO 24/06/2020; ACEPTADO 19/07/2020] \\ http://doi.org/10.25267/Riparia.2020.v6.02
}

\section{RESUMEN}

El asentamiento de Puente Melchor ha sido objeto de diversas intervenciones arqueológicas de urgencia que han ido revelando el carácter artesanal del mismo. Su contexto geográfico, litoral y fuertemente antropizado, dificulta el conocimiento histórico del mismo. La teledetección y fotogrametría aéreas y la generación de distintas visualizaciones de los productos generados permiten detectar elementos histórico-arqueológicos en áreas donde aplicar una metodología invasiva se vuelve complicado. Pero su principal ventaja es la capacidad de integración e interacción con fuentes histórica o arqueológicas tradicionales.

Palabras Claves: Puente Melchor, Fotogrametría, Teledetección Aéreas, Visualizaciones, MDT, Calzada Romana.

1 Doctoranda UCA. Laboratorio de Historia del IVAGRO. Edificio Instituto Investigación Ciencias Sociales Campus de Jerez, 11405 Jerez de la Frontera, Cádiz.

Isabel Rondán Sevilla, "El asentamiento de Puente Melchor (Puerto Real, Cádiz)”, RIPARIA 6 (2020), 30-73. 
RIPARIA VOL. 6 (2020)

\section{Abstract}

The Puente Melchor settlement has been the subject of various archaeological interventions; these have shown his industrial character. On account of his geographic context, coastal and anthropized, is very difficult detects the historical information. Aerial remote sensing and photogrammetry and the different visualizations of the generated products allow to detect historical-archaeological elements in areas where applying an invasive methodology becomes complicated. However, his advantage more important is the capacity to integrate and be complement with traditional historical or archaeological sources.

KEY WORDS: Puente Melchor, Aerial Photogrammetry and Remote Sensing, Visualizations, DTM, Roman Roadway. 


\section{Introducción}

El asentamiento de Puente Melchor se encuentra en el término municipal de Puerto Real, en el saco interno de la Bahía de Cádiz (fig. 1). Esta situación geográfica proporcionó diversos factores que facilitaron el desarrollo y crecimiento del asentamiento, especialmente por los recursos de los que disponía el entorno para la producción alfarera y, por otro lado, al encontrarse junto al mar, la explotación de los bienes que ese medio ofrecía, así como su potencial como medio de comunicación. En parte por esta razón se ha definido a Puente Melchor como un gran centro de producción cerámica, cuya adscripción cronológica, según el estudio de esa manufactura, se inicia a mediados del siglo I a.C. y perdura hasta principios del siglo $\mathrm{V}$ d.C. ${ }^{2}$, aunque otros estudios extienden la cronología hasta principios del siglo VII d.C. ${ }^{3}$

El yacimiento fue documentado en 1946 con la sustitución de un paso a nivel por un paso superior sobre las vías del ferrocarril en la N-IV en el kilómetro 667, descubriéndose abundantes restos anfóricos y escombreras cerámicas durante el desmonte ${ }^{4}$. El asentamiento se encuentra en una zona fuertemente antropizada afectado por vías férreas, autovía, subestación eléctrica y urbanizaciones residenciales, además de canalizaciones y conducciones subterráneas de todo tipo y de diferentes cronologías.

En los últimos años ha sido objeto de diferentes modificaciones e intervenciones, hecho que ha ido marcando el conocimiento histórico de Puente Melchor. Es decir, la información que se ha ido aportando de este asentamiento es fruto de una serie de excavaciones de urgencia en diversas zonas como consecuencia

2 C. Chacón Mohedano, Nuevas estructuras arqueológicas documentadas en el yacimiento de Puente Melchor, Puerto Real, Cádiz, Mainake XXXIV, 2013, 77-97.

3 L. Girón Anguiozar, Las cerámicas comunes del alfar romano de Puente Melchor (Puerto Real, Cádiz): un ensayo de clasificación de las formas abiertas, Herakleion 3, 2010, 105-162.

4 C. Pemán Pemartín, Alfares y embarcaderos romanos en la provincia de Cádiz, A.E.A. vol. 32, nº 99, 1959, 169-173.

“El asentamiento de Puente Melchor (Puerto Real, Cádiz): integración de..." 
de las distintas afecciones urbanísticas. A pesar de la complicada realidad de este tipo de intervenciones, han arrojado importantes hallazgos para la comprensión de la bahía en la Antigüedad.

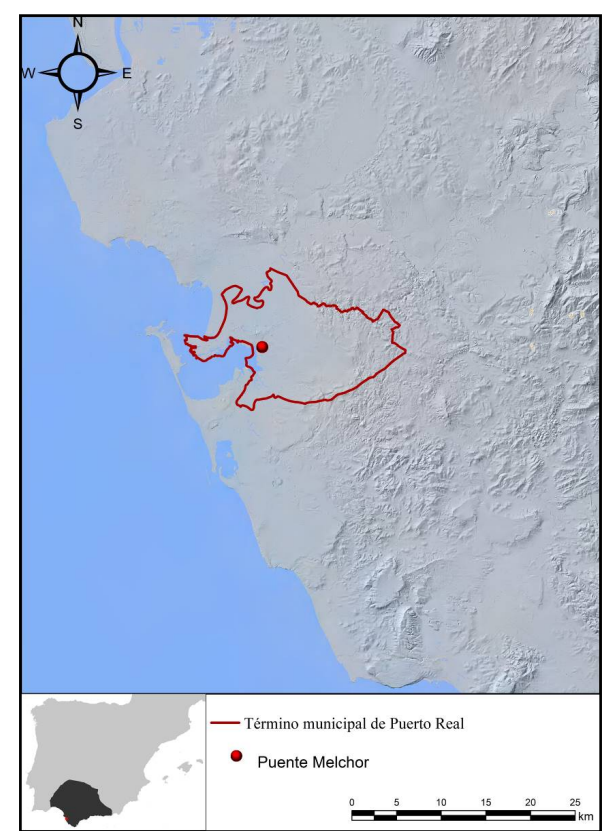

Fig. 1: Localización del asentamiento de Puente Melchor actualmente y en la Bética.

La teledetección aérea y el tratamiento de imágenes permite generar una documentación muy interesante que complementa la información arrojada por la arqueología y las fuentes clásicas. La búsqueda de elementos en el terreno, susceptibles de ser analizados desde una perspectiva histórica, es el principal objetivo de esta metodología, los que deminaremos de aquí en adelante anomalías o alteraciones en el terreno. En este sentido, para el caso de Puente Melchor, la identificación de la calzada romana, excavada en parte en una de las intervenciones arqueológicas que se describirán a continuación, resulta esencial para entender la organización espacial del asentamiento. En la consecución de 
fines similares las herramientas y técnicas empleadas para este trabajo se han mostrado como muy positivas ${ }^{5}$.

\section{Descripción de intervenciones arqueológicas de interés en Puente Melchor}

Las intervenciones arqueológicas más relevantes en Puente Melchor y su entorno se han desarrollado en 1994, 1996, 2003, 2004 y 2007/08. A continuación, se describen brevemente las estructuras documentadas durante estos años. No se van a abordar las descripciones de tipologías de los materiales cuya importancia para la adscripción cronológica del asentamiento es esencial, pero que se encuentran muy bien reflejadas en otros trabajos sobre Puente Melchor. Es decir, lo que interesa en este punto es resumir parte de la información arqueológica actual, situando el centro de atención en los elementos inmuebles documentados más que en los muebles, así como situarse en el espacio geográfico objeto del presente estudio (fig. 2).

La excavación de $1994^{6}$ tuvo lugar por la construcción de la variante de la N-IV, la metodología que se aplicó fue la de una malla de cuadrículas de $2,5 \times 5 \mathrm{~m}$ siguiendo el eje de la carretera, pero las dimensiones de lo planteado y la necesidad de obtener una panorámica general hizo que se excavara en damero, estableciéndose un punto de partida en la zona más elevada y excavando 10 cuadrículas hacia al norte y otras tantas hacia el sur. En la zona excavada hacia el norte, se documentó un enorme vertedero, conformado, principalmente, por restos de la producción anfórica, con diversos estratos donde predominan fallos de cocción y materiales constructivos mezclados con otros

5 V. Mayoral Herrera, Arqueología aérea y teledetección en el suroeste peninsular. La experiencia del Proyecto Riteca II, La Revalorización de zonas arqueologías mediante técnicas no destructiva, Anejos de AEspA, LXXV, 2016b, 24-40. Consejo Superior de Investigaciones Científicas, Mérida; M. SOMraK, S. DŽEROSKI Y Ž. KOKALJ, Learning to Classify Structures in ALS-derived Visualizations of Ancient Maya Settlements with CNN, Remote Sensing 12, 2020, 1-20.

6 Dirigida por Luis Cobos Rodríguez y Luis Aguilera Rodríguez.

“El asentamiento de Puente Melchor (Puerto Real, Cádiz): integración de..." 
elementos procedentes de la reparación de algún horno. En cuanto a las cuadrículas orientadas hacia el sur, arrojaron una información un tanto diferente, con restos murarios y áreas habitacionales. Cabe destacar un muro testáceo de unos $15 \mathrm{~m}$ y diversos recintos cuadrangulares y rectangulares con elementos relacionados con la producción anfórica, hornos y otros elementos para el tratamiento de dicha manufactura. En una de las habitaciones cuadrangulares se documentaron dos hornos, uno de ellos de tendencia circular con una parrilla conservada con 90 respiraderos sujeta por una columna central de $1,5 \mathrm{~m}$ de diámetro y casi $3 \mathrm{~m}$ de altura; el otro horno, basado en una parrilla formada por una serie de brazos perpendiculares al praefurnium descansando en una bóveda y con unas dimensiones generales similares al anterior. Al suroeste de esta habitación se excavó otra rectangular de unos $300 \mathrm{~m}^{2}$, subdividida en algún momento en tres, con muros construidos de restos de ánfora, y donde cabe destacar una pileta circular de 2,80 m de diámetro y 0,60 $\mathrm{m}$ de profundidad. Se excavaron otras habitaciones similares, algunas con restos de pavimentos de opus signinum, muros sillarejos y restos de torno de pie alfarero, canalizaciones de agua entre las habitaciones, entre otros elementos, además de dos hornos, probablemente uno de ellos para la producción de vidrio.

La intervención de urgencia de $1996^{7}$ tuvo lugar por la construcción de una rotonda al sureste de la zona anterior que de nuevo sacó a la luz restos arqueológicos. En la primera zona excavada (la aleta noroeste de la rotonda) se documentaron tres habitaciones: la primera con tres de sus muros de sillares, tégulas y galbos anfóricos, conservaba una pequeña parte de su suelo marmóreo; la segunda, medianera con la anterior, donde solo se documentó tierra apisonada; la tercera, conservaba un muro de opus testaceum y un depósito de restos cerámicos con una capa de ceniza. Además, aparecieron abundantes restos anfóricos,

7 Dirigida por Luis Cobos Rodríguez y Maximino Pérez Roa. 
cerámica común de cocina y mesa (cazuelas, cuencos y lebrillos), sigillatas hispánicas y gálicas y dos conjuntos de monedas con una cronología de la primera mitad del siglo I d.C. y desde siglo II d. C. hasta el último tercio del siglo III d.C., respectivamente. En el estribo opuesto de la rotonda se documentaron diversas habitaciones divididas por dos muros sillarejos y de fragmentos cerámicos y otro muro perpendicular a estos que subdividía los espacios. Conservaba en gran medida el pavimento, por debajo del que aparecían otros muros de construcciones anteriores. En el exterior se documentaron dos muros construidos con elementos cerámicos y una especie de pileta hecha en la arcilla y enlucida de opus caementicium.

Se excavó un tercer sector con motivo del paso de una tubería de agua potable de unos $4 \mathrm{~m}$ de anchura. Se documentó un gran vertedero cerámico interrumpido al norte por un muro de sillarejo, dos hornos y una serie de piletas alargadas. La zona correspondiente a las piletas resultó de las más interesantes, se trataba de un conjunto con orientación oeste-este, con un espacio abierto amplio delimitado por muros de sillares y dentro una pileta aislada con revestimiento hidráulico con desagüe. Se excavó una pareja de hornos muy bien conservados con pasillo de acceso a la cámara de cocción.

La intervención llevada a cabo en $2003^{8}$ se desarrolló por la acometida de un nuevo ramal de aguas proveniente del Barrio Jarana en dirección al Puerto de Santa María que cruzaba por el entorno de Puente Melchor. Se modificó el recorrido previsto de la tubería al documentarse un área similar a la excavada en 1994. Se encontró también una zona de necrópolis con un total de 21 enterramientos, la mayoría incineraciones (14 cremaciones y 7 inhumaciones), mostrando tumbas de diversas tipologías.

8 Dirigida por Luis Aguilera Rodríguez.

"El asentamiento de Puente Melchor (Puerto Real, Cádiz): integración de..." 
También aparecieron ánforas clavadas en el suelo marcando espacios?.

En $2004^{10}$, debido a la obra de duplicación de la carretera N-IV para unir Puerto Real y Tres Caminos, se realizaron más intervenciones. Se excavó lo que se ha descrito como una villa romana con una superficie de $2.009 \mathrm{~m}^{2}$, un edificio con unas dimensiones de 77,30 $\mathrm{m}$ de largo y $26 \mathrm{~m}$ de ancho. Pero esta no es el área total del recinto porque los muros continuaban bajo la antigua $\mathrm{N}-\mathrm{IV}$.

Según los estudios de materiales la supuesta villa estuvo en funcionamiento entre la segunda mitad del siglo II d.C. y finales del siglo III d.C. Cabe destacar el mosaico que apareció durante esta intervención, definido como un elemento excepcional por su conservación, tamaño y calidad al compararlo con otras piezas del entorno. El cuerpo central está presidido por una representación del dios Baco muy joven, que aparece junto a motivos figurativos y geométricos. En los ángulos del enmarque del cuadro aparecen cuatro figuras, las dos superiores son dos cráteras y en los inferiores dos aves, en el derecho un loro y en el izquierdo un ave acuática. En el cuerpo inferior aparecen representadas cuatro figuras humanas y motivos geométricos, se han identificado como Apolo, Pan, Ariadna y Sileno. Los personajes mitológicos que componen el cortejo al dios Baco están coronados con pámpanos, atributo característico del dios principal. Mientras que las representaciones de Apolo y Pan fijan su mirada en Ariadna y Sileno estos últimos miran hacia arriba, hacia Baco. Además, aparecen pinturas murales, siguiendo unas técnicas documentadas en otros yacimientos romanos similares con distintas capas de

9 M. L. Lavado Florido, El complejo industrial de Puente Melchor: el centro productor, la organización del espacio y su área de influencia, en L. LAGósTENA y D. BERnAL (eds.), Figlinae Baeticae: Talleres alfareros y producciones cerámicas en la Bética romana (ss. II a.C.-VII d.C): Actas del Congreso Internacional. BAR International Series, 1266, Cádiz, 12-14 de noviembre de 2003, 2, 2004, 473-488.

10 Dirigida por $\mathrm{M}^{\mathrm{a}}$ Luisa Lavado Florido. 
revestimiento, una última muy delgadas y cuyos motivos pictóricos han sido divididos en cuatro grupos: imitación de materiales nobles (mármol brocatel), líneas geométricas enmarcadas en casetones, motivos florales y un zócalo liso verdoso enmarcado con líneas estrechas burdeos y en medio una línea ancha amarilla lisa. Las características formales y estilísticas del mosaico hacen que se feche hacia finales del siglo II o primer cuarto del siglo III d. C. ${ }^{11}$

En definitiva, y teniendo en cuenta que no se ha podido excavar en su totalidad, se ha interpretado este gran edificio como una villa distinguiéndose, una pars urbana y otra pars rustica. Una estancia con la exedra de cabecera identificada como una zona de baños o ninfeo, el triclinium con el mosaico de Baco y otras estancias con pinturas parietales y otros ricos ornamentos, además de que parece que tenía una segunda planta, a la que se accedía desde un extremo del patio, sería la pars urbana. Mientras que la pars rustica, a continuación de esta, podría estar dedicada a la fabricación de ánforas o a una zona de almacenes o de servicio para la administración ${ }^{12}$.

En 2007 y $2008^{13}$ continuaron las intervenciones en Puente Melchor. En una primera fase se excavó en la parcela situada al noroeste de la intervención de 1994, junto a la carretera de circunvalación y del puente construido. Se documentaron hasta 32 estructuras funerarias. El recinto de esta necrópolis estaba

11 M.L. Millán Salgado, M.C. Gómez Bueno, El mosaico de la villa romana de Puente Melchor: estudio histórico-artístico y tratamiento de conservación, ROMVLA, 11, 2012, 116-132; A. Durán Macías, El mosaico de Baco (Puente Melchor, Cádiz), arqueología arqueometría y musealización, Revista de Investigación y Letras, $\mathrm{N}^{\circ}$ 1, 2017, Universidad de Cádiz, 114-122.

12 M.L. Lavado Florido, Memoria final de la intervención arqueológica llevada a cabo en proyecto de la duplicación de la carretera N-IV. Tramo final: variante Puerto RealTres Caminos del P.K. 671,8. Cádiz, Anuario de Arqueología de Andalucía, 2004, 2, Consejería de Cultura, Sevilla, 106-110.

13 Primera fase de estas intervenciones dirigida por Beatriz González Toraya, desde febrero de 2007 a marzo de 2008. En una segunda fase asume la dirección Cristina Chacón Mohedado.

“El asentamiento de Puente Melchor (Puerto Real, Cádiz): integración de..." 
delimitado por un muro de ánforas colocadas verticalmente y dentro el espacio queda dividido por un muro de sillarejo de piedra ostionera. Además, se documentó un muro de opus testaceum de 22,9 $\mathrm{m}$ de longitud asociado a pavimentos construido con elementos anfóricos. Pero sobre todo destaca el hallazgo de $27 \mathrm{~m}$ de calzada romana, probablemente un tramo de la vía Augusta, a una cota de $-20 \mathrm{~cm}$, habiendo sido afectada por el arado. Atravesando de manera diagonal la calzada, con orientación noroeste-sureste, se documentó un tramo del acueducto subterráneo del siglo XVIII de 11,65 m.

En una segunda fase, con motivo de la conversión de la vía férrea en Línea de Alta Velocidad y el desmantelamiento del puente Melchor, se desarrolló una intervención a unos $50 \mathrm{~m}$ al sureste del antiguo puente, junto a las vías del tren. En esta fase se documentó un testar cerámico altoimperial en el talud de la vía, varios muros que dividían estancias, donde destacan los de opus testaceum, y un muro de ánforas dispuestas verticalmente. Cabe destacar una estructura en especial, una cisterna semiexcavada en el nivel geológico, formada por tres cámaras abovedadas comunicadas entre ellas y que parecen haber estado cubiertas por bóvedas de sillares de medio punto de piedra ostionera. El interior estaba revestido con opus hidráulico. En una de las cámaras se apreciaron diferentes tongadas del enlucido, lo que indica sus diversas reparaciones y mantenimiento. Además, se detectó una gran canalización que recorre la zona norte de la cisterna en sentido este-suroeste y que conservaba parte de su cubierta y parte del enfoscado de opus signinum. Otro elemento interesante era un pozo excavado en el geológico, documentándose $4 \mathrm{~m}$ de estratigrafía. 

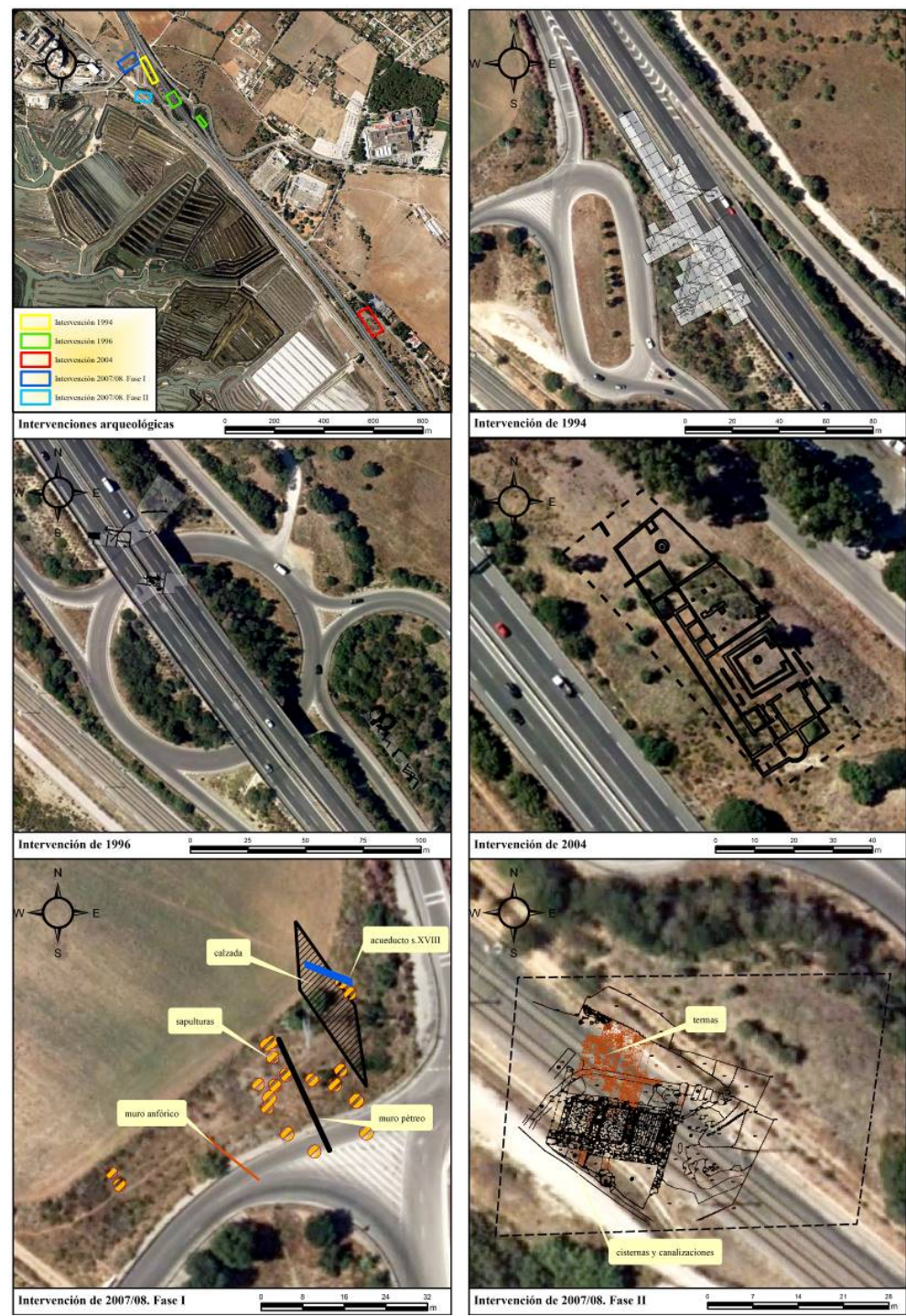

Fig. 2: Digitalización de las intervenciones arqueológicas en Puente Melchor ${ }^{14}$.

14 A partir de M.L. Lavado Florido, El complejo industrial de Puente Melchor...474, 480-482; A. Durán Macías, El mosaico de Baco... 115; C. Chacón Mohedano, Nuevas estructuras arqueológicas...81 y 85 .

"El asentamiento de Puente Melchor (Puerto Real, Cádiz): integración de..." 
Parece que, una vez amortizado el complejo hidráulico compuesto por cisternas y canalización, se construyón un edificio termal, reutilizándose muchos de los elementos del conjuto anterior. El hipocausto se construye sobre la canalización amartizándola. Se intuye una continuidad de las estructuras hacia el norte mediante una habitación ya desaparecida y se apreciaron diversas reconstrucciones ${ }^{15}$.

\section{Objetivos y materiales}

Como se ha ido señalando en las breves descripciones de algunas de las intervenciones arqueológicas llevadas a cabo en el entorno de Puente Melchor, se trata de una zona con muchas actuaciones y modificaciones de su ordenamiento original. Este hecho no es baladí porque, junto al contexto ribereño del asentamiento, condiciona en gran medida los objetivos planteados, los materiales y metodología usados en este trabajo:

- El uso de datos LiDAR y Modelos Digitales de Elevaciones como documentación susceptible de ser analizada desde una perspectiva histórica, especialmente interesante para el análisis del paisaje histórico, y que pueda sumar información e integrarse con lo que las fuentes clásicas y los trabajos arqueológicos ya han revelado.

- La implementación de tratamientos de visualización y herramientas de los Sistemas de Información geográfica (GIS de aquí en adelante) en el análisis de los datos anteriores, de tal manera que se consiga una mejora cualitativa en la interpretación de los posibles elementos históricos detectados.

- La aproximación a un posible modelo de restitución del marco geográfico del entorno del yacimiento con cartografía antigua. El contexto geográfico del asentamiento, de carácter ribereño, complica la consecución de este objetivo, los

15 C. Chacón Mohedano, Nuevas estructuras arqueológicas...79-88. 
cambios de eustatismo, por ejemplo, son de enorme complejidad a la hora de ser tratados y modelados. Existen algunos marcadores que podrían ser útiles, así como diversos trabajos técnicos en torno a ese tema, de manera que debido al propio contexto geográfico de Puente Melchor es importante una aproximación a ese marco para intentar comprender mejor el asentamiento.

- La interacción, integración e interpretación histórica de los resultados obtenidos con estas técnicas y los arrojados por la excavación arqueológica.

- Búsqueda y propuesta de protocolos de actuación basados en una metodología no invasiva que sean extrapolables a otros asentamientos de características similares. Basados en las técnicas de visualización y análisis aplicadas a los datos obtenidos mediante fotogrametría y análisis cartográfico, podrían ser complementados con la aplicación de otras técnicas, como la geofísica.

En cuanto a los materiales o la documentación con los que se ha trabajado para ir resolviendo los anteriores objetivos, podrían definirse como de dos tipos: por un lado, datos de carácter histórico-arqueológico y, por otro, datos geográficos de referencia digital.

En el caso del primer grupo, se encuentran las planimetrías, fotografías y datos extraídos a partir de las intervenciones arqueológicas descritas. Estos, en gran medida, aportan los límites espaciales en cuanto a la zona de estudio, han sido georreferenciadas y digitalizadas en un GIS para poder entenderlas en su conjunto y no de manera aislada, no sólo entre ellas sino con el resto de documentación y materiales empleados. De manera que la base donde se integren todos los elementos será un GIS.

Por otro lado, se ha utilizado cartografía histórica de la zona para entender mejor el entorno geográfico de Puente Melchor, 
especialmente para trabajar con representaciones con menos elementos antrópicos que las actualmente disponibles. En este caso, destaca el Plano del Puerto de Cádiz levantado por el Brigadier de la Real Armada D. Vicente Tofiño de San Miguel en $1789^{16}$, que ha sido georreferenciado y utilizado como modelo, pero también se ha consultado otra cartografía histórica de gran interés para comenzar a comprender el espacio "original" ribereño de este asentamiento ${ }^{17}$.

De suma importancia han sido las referencias aportadas por distintas investigaciones y trabajos sobre los cambios de eustatismo de la zona, con todas las variables y complejidad de este tema, así como la información sobre el paleopaisaje. Y, por supuesto, lo datos recogidos en campo, sobre todo los puntos tomados con GPS diferencial en determinadas áreas de interés, especialmente los que tienen que ver con el paleopaisaje y del que aún queda algún testigo.

En el segundo grupo de materiales, lo que se ha definido como datos geográficos de referencia digital, son algunos datos vectoriales de interés, donde tienen una especial importancia la línea de costa actual ${ }^{18}$ o las láminas de agua y corrientes para el estudio de las áreas de marismas y salinas ${ }^{19}$. Por otro lado, las fotografías aéreas tanto actuales como históricas, recogidas en

16 V. Tofiño de San Miguel, Brigadier de la Real Armada, Plano del Puerto de Cádiz. [Mapa]. 1:30.000. Servicio de Biblioteca, Archivos Topográficos y Cartoteca del IGN.: Madrid, 1789: Depósito Hidrográfico. Recuperado en https://www.ign.es/web/catalogo-cartoteca/resources/html/000138.html

${ }_{17}$ Cartografía Histórica de la Bahía De Cádiz, Mapas y Planos extraídos de la Biblioteca Nacional de España. en https://milan2.es/PortalSanFernando/SanFernandoCartografia BNE.html

18 Instituto Geográfico Nacional, Línea de Costa Actual, Centro de descarga. Recuperado en http://centrodedescargas.cnig.es/CentroDescargas/catalogo.do?Serie=CAANE 19 Instituto de Estadística y Cartografía de Andalucía. Base Cartográfica de Andalucía $1: 10.000 \quad-\quad$ BCA10. Recuperado de https://www.juntadeandalucia.es/institutodeestadisticaycartografia/prodCartografia/bc bca.htm 
diferentes plataformas ${ }^{20}$, en las que cabe destacar, además de la de máxima actualidad, ortofotografías de los años 2004, 2006 y 2008, pero, sobre todo, las del vuelo Americano Serie B (1956-57) y la del vuelo Interministerial (1973-86), esenciales para trabajar con las planimetrías de las excavaciones o para entender la fuerte intervención de la que ha sido objeto toda esta área. Y los datos $\mathrm{LiDAR}^{21}$ sobre los que se han aplicado diversos tratamientos que se mostrarán más adelante, tanto sobre la nube de puntos como sobre el modelo resultante, trabajando con las hojas 216-4046, $216-4048,218-4046$ y $218-4048^{22}$.

El LiDAR (Light Detection and Ranging) es un sistema activo, dentro de las tecnologías de teledetección, que mediante un sensor emite un haz de luz láser sobre la superficie lo que permite hacer mediciones y cálculos. Quizás la ventaja más relevante de esta tecnología sobre la fotogrametría es que tiene la capacidad de penetrar en la vegetación, de manera que es posible obtener información de la superficie topográfica. Esto último es esencial para el uso del LiDAR en la investigación histórico-arqueológica, pero, además, el hecho de que sea posible clasificar los puntos de la nube obtenida con el fin de eliminar, siempre en la medida de

20 Instituto Geográfico Nacional, Ortofotos e imágenes satélites, Centro de descarga. Recuperado en

http://centrodedescargas.cnig.es/CentroDescargas/catalogo.do?Serie=CAANE\# ;

REDIAM, Ortofoto Digital Pancromática de Andalucía 1956-57, Servicio WMS.

Recuperado en

http://www.juntadeandalucia.es/medioambiente/mapwms/REDIAM Ortofoto Anda lucia 1956?

21 Instituto Geográfico Nacional, LiDAR 1ª Cobertura 2008-2015, Centro de Descarga. Recuperado

en http:// centrodedescargas.cnig.es/CentroDescargas/catalogo.do?Serie=CAANE

22 Se ha utilizado esta fuente conociendo la existencia del proyecto fotogramétrico Digital - Lidar del ámbito de las cuencas hidrográficas de Guadalete y Barbate en 2008, cuya resolución está por encima de los datos LiDAR del IGN. Pero con motivo del Estado de Alarma el servicio no se encontraba operativo.

"El asentamiento de Puente Melchor (Puerto Real, Cádiz): integración de..." 
la posible, la vegetación o elementos antrópicos como las carreteras $^{23}$ es la base de su uso en este trabajo.

\section{Aplicación de diversos tratamientos y análisis sobre imágenes aéreas, datos LiDAR y los modelos generados}

La denominada Arqueología Aérea es una herramienta más para el conocimiento y reconstrucción de nuestro pasado. Usa la prospección con medios aeronáuticos para detectar vestigios antrópicos en medios naturales mediante la heterogeneidad del aspecto del suelo y la vegetación ${ }^{24}$. Las formas en las que esas diferencias se muestran son diversas y por tanto el conocimiento y uso de los tratamientos al registro aéreo, normalmente fotografías, es esencial para obtener resultados positivos.

El uso de ortofotografías "históricas" permiten tanto mostrar un estado con menos intervención como ser esenciales para georreferenciar elementos. Pero también es interesante trabajar sobre sus posibles visualizaciones y ponerlas en relación con otros elementos, de tal manera que en determinadas ocasiones revelan anomalías o alteraciones que podrían pasar inadvertidas. Estas imágenes son la representación de una serie de datos numéricos que pueden ser tratados con distintos algoritmos modificando su representación, pero sin alterar el contenido.

En definitiva, lo que interesa es detectar anomalías, que puedan corresponder con elementos histórico-arqueologicos en el terreno a través de los productos obtenidos de vuelos fotogramétricos, LiDAR, etc. y aplicar una serie de filtros a las imágenes obtenidas a modo de Prospeccion Visual en la Distancia que luego pueden ser corroborados en campo.

23 No para tomar los datos bajo esta, no es viable con esta técnica, pero sí para modelar el espacio y acercarse a su morfología original.

24 J. Del Olmo Martín, Arqueología Aérea en Castilla y León, La Revalorización de zonas arqueologicas mediante técnicas no destructivas, Anejos de AEspA, LXXV, 2016, 197. Consejo Superior de Investigaciones Científicas, Mérida. 
Siguiendo esta premisa se ha seleccionado una zona concreta y más reducida para que sea posible, por ejemplo, percibir y detectar modificaciones en la visualización sobre el yacimiento que puedan corresponder con elementos soterrados. En el caso del sector noroeste del área, coincidiendo con una zona donde se ha intervenido arqueológicamente, tanto en la ortofoto del Vuelo Interministerial como en la del Vuelo Americano, se aprecian elementos que podrían corresponder con vestigios arqueológicos, pero que no son tan fácilmente detectables en la imagen original o en la ortofoto más actual. Para ello la modificación de la visualización se ha desarrollado haciendo cálculos sobre los raster originales, además de cortes porcentuales en el histograma como muestra la figura 3. De tal manera que se señalan aquellas alteraciones que ya se detectan en la imagen original y otras que se intensifican tras la modificación en su visualización. Esto no quiere decir que las alteraciones destacadas se correspondan siempre con elementos arqueológicos, aunque se verá en el apartado de Resultados que en determinados casos son evidentes, pero sí que se trata de una sencilla pero eficaz técnica para "mejorar" la visualización.

Los datos LiDAR del Instituto Geográfico Nacional (IGN), en el caso de la primera cobertura, tienen una densidad de puntos de 0,5 puntos $/ \mathrm{m}^{2}$. Para una zona relativamente pequeña como la que aquí interesa no son datos con mucha resolución, pero trabajando con el LAS $^{25}$ en distintos software es posible, a través de la interpolación, mejorar un poco el resultado en la creación del Modelo Digital del Terreno (MDT de aquí en adelante).

25 Formato de archivo estándar para el intercambio de datos LiDAR.

“El asentamiento de Puente Melchor (Puerto Real, Cádiz): integración de..." 


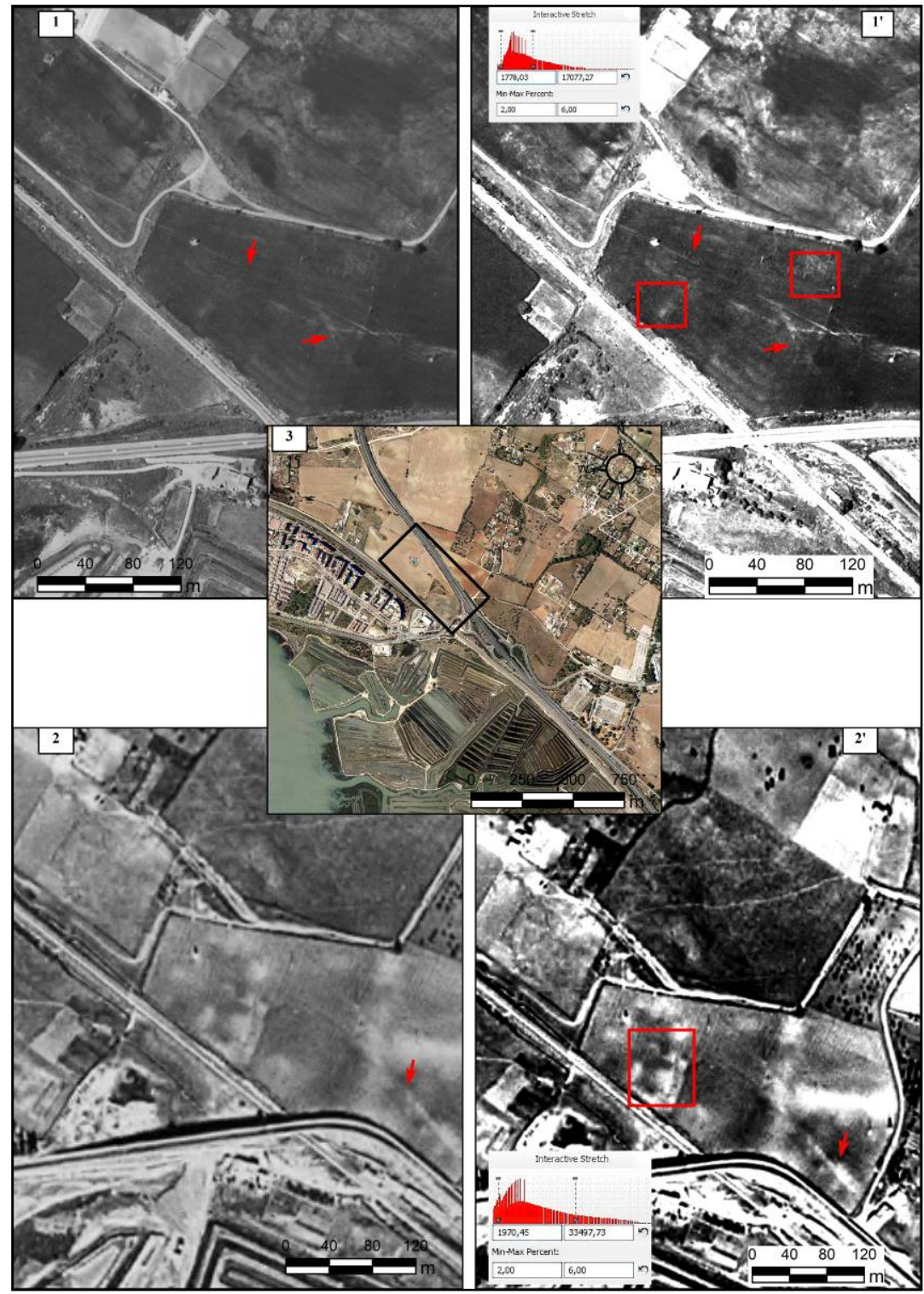

Fig. 3: 1 y 1' alteraciones en ortofoto del vuelo Interministerial sin tratar y tratada, respectivamente; 2 y 2 ' alteraciones en ortofoto del vuelo Americano sin tratar y tratada, respectivamente; 3 imagen de referencia espacial. 
Tanto en ArcGIS como en Global Mapper, programas en los que se han trabajado estos datos, el procedimiento general para obtener el MDT es el mismo: visualización del archivo LAS, la nube de puntos, aquí se puede apreciar la densidad de los mismos para tenerlo en cuenta cuando se marquen los parámetros de interpolación; filtrado de los puntos y los retornos; y rasterizado o creación de la malla mediante la interpolación que sea oportuna. Con este proceso se ha obtenido un MDT del área de interés del que extraemos las curvas de nivel cada 0,5 m (fig. 4).

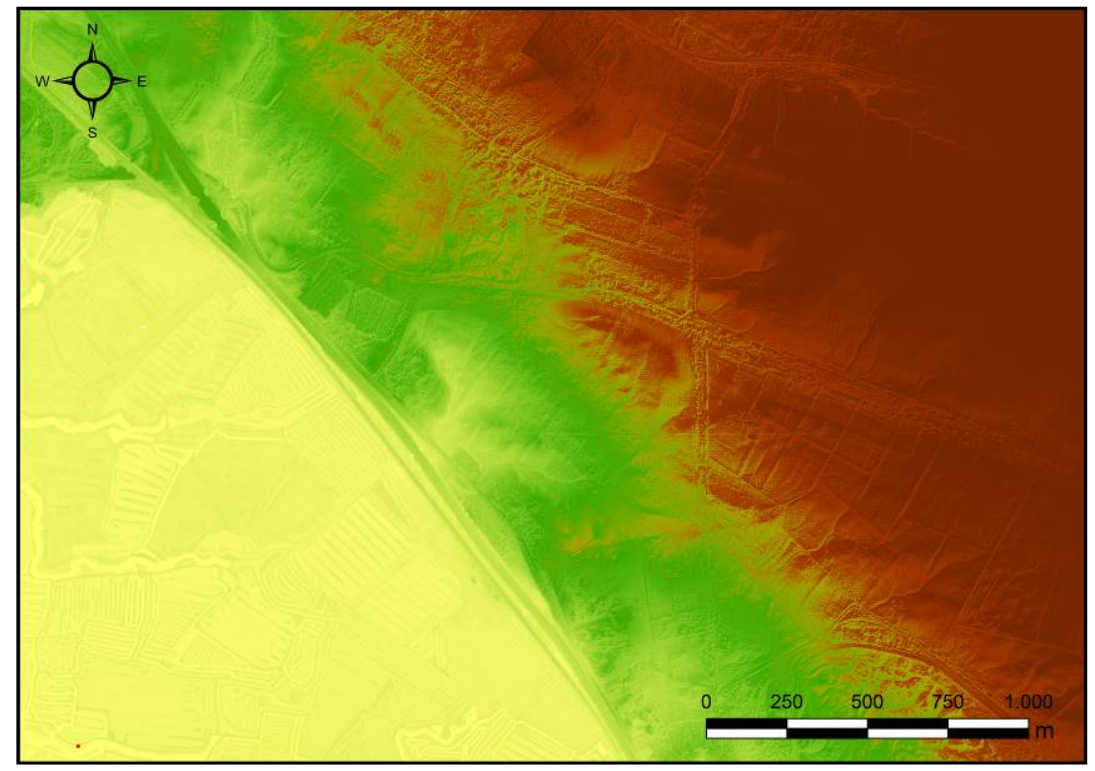

Fig. 4: Modelo Digital del Terreno del entorno de Puente Melchor.

Una vez generado el MDT se han aplicado una serie de algoritmos para mostrar opciones de visualización que, en determinadas ocasiones, han resultado muy interesantes para detectar elementos arqueológicos en el terreno. La idea es la misma que la planteada anteriormente, modificar la visualización del raster, en este caso del MDT, para poder detectar elementos en el terreno susceptibles de ser interpretados desde una perspectiva histórico-arqueológica.

"El asentamiento de Puente Melchor (Puerto Real, Cádiz): integración de..." 
El uso e implementación de herramientas y cálculos de visualización para estos modelos generados a partir de datos LiDAR no tiene un largo recorrido en la investigación históricoarqueológica. La técnica de visualización más extendida en este ámbito es la del sombreado (shading), posiblemente porque se trata de una imagen más intuitiva y también debido a que gran parte de las publicaciones científicas modernas se limitan a la exposición de imágenes en escala de grises. La comprensión y conocimiento de estas herramientas por parte del investigador de la Historia del Territorio y el Paisaje son importantes por la consiguiente habilidad de análisis e interpretación de las mismas desde su disciplina.

Las técnicas de visualización de un MDT para, en este caso, detectar estructuras negativas o positivas soterradas, han sido divididas en cuatro grupos por algunos de los investigadores que más están trabajando en este sentido en los últimos años ${ }^{26}$. El sombreado y métodos de iluminación del relieve es el que tiene más tradición en su empleo, se basa en la luz direccional, simulando un determinado ángulo de iluminación del sol como base para detectar elementos. El segundo grupo serían los modelos de color fundido, aunque dan buenos resultados en áreas costeras y planas no ocurre lo mismo en zonas con una topografía más compleja. Por otro lado, los denominados métodos de manipulación del MDT, el conjunto de herramientas de análisis morfométricos que los GIS ofrecen. Y, finalmente, los filtros de procesamiento de imágenes concretos para detectar variaciones de alta frecuencia como el filtro laplaciano para el realce de bordes y elementos lineales.

\footnotetext{
26 B. ŠTUlar, Ž. KOKALJ, K. OŠTiR, L. Nuninger, Visualization of lidar-derived relief models for detection of archaeological features, Journal of Archaeological Science 39, 2012, 3355-3357.
} 
El software Relief Visualization Toolbox $(R V T)^{27}$ fue diseñado para analizar con fines arqueológicos modelos de elevaciones, de manera que resulta especialmente interesante para la identificación de características relevantes en el terreno a pequeña escala. Aunque es indiscutiblemente eficiente para otros campos de estudio donde la extracción automática de datos del terreno sea el objetivo: geografía, silvicultura, hidrología, etc. Los diferentes resultados de visualización que se obtienen podrían ser divididos en tres grupos, según el objeto de los cálculos: la propia topografía del área; la iluminación, y sombreado, y los observadores; y modelos mixtos que conjugan ambas perspectivas. Dadas las características geomorfológicas de la zona que interesa, que además de muy antropizada es relativamente plana, con una topografía con pendientes muy moderadas en parte debido a su ubicación costera, se van a seleccionar cuatro visualizaciones que se describen brevemente.

- Simple Local Relief Model (SLRM) ${ }^{28}$ : elimina las variaciones de altura de elementos morfológicos a gran escala como valles para resaltar los de pequeña escala.

- Sky-View Factor $(S V K)^{29}$ : surge para solventar algunos inconvenientes de iluminación del bill-shading, por ejemplo, se basa en la iluminación simulada con luz difusa midiendo el cielo visible desde un punto dado. Según esta idea, los elementos en superficies como crestas reciben mayor iluminación y son más brillantes que los que se encuentran en el fondo de un valle empinado. Esto se debe a que es visible una mayor parte del cielo desde el primero que desde el

27 Z. KOKALJ, K. ZAKŠEK, K. OŠTIR, P. Pehani, K. ČOTAR, Relief Visualization Tollbox, ver. 1.3 Manual, 2016.

28 R. Hesse, LiDAR-derived Local Relief Models: a new tool for archaeological prospection, Archaeological Prospection, 17 (2), 2010, 67-72; Z. KOKALJ, K. OŠTIR, K. ZAKSEK, Visualization of lidar derived relief models, en R.S OpITZ, D. C. COWLEY (eds.), Interpreting Archaeological Topography: Airborne laser scanning, 3D data and ground observation, 2016, 107-108. Oxbow Books.

29 K. ZAKSEK, K. Oštir, Ž. KOKALJ, Sky-View Factor as a Relief Visualization Technique, Remote Sensing, 3, 2011, 400-404.

"El asentamiento de Puente Melchor (Puerto Real, Cádiz): integración de..." 
segundo. De manera que se mostrarán las superficies elevadas y sus elementos con colores claros y los que se encuentran en depresiones de colores más oscuros.

- Local Dominance $(L D)^{30}$ : muestra la dominancia de un supuesto observador desde un determinado píxel para el área circundante. La dominancia hace referencia al ángulo de inclinación con el que el observador ve la superficie terrestre de esa área, será mayor en puntos con protuberancias o pendientes positivas y menos en depresiones. Ha dado buenos resultados para detectar elementos muy sutiles del terreno como límites agrarios, restos de cultivos o túmulos funerarios muy erosionados.

- Morphometric Protection Index-Red Relief Image Map (Stereo MPIRRIMs $)^{31}$ : esta visualización no está creada directamente con RVT aunque conjuga algunos de sus resultados. Pone el foco en la diferencia entre concavidades y convexidades a través de otras técnicas de visualización, Openess Positive y Negative, se basan también en la iluminación difusa estimando un ángulo de elevación medio del horizonte con un radio de búsqueda predefinido. El positivo arroja información sobre las concavidades $y$ el negativo sobre las convexidades.

\footnotetext{
30 Z. KOKALJ, ET AL., Relief Visualization...7.

31 H. Kaneda, T. ChibA, Stereopaired Morphometric Protection Index Red Relief Image Maps (Stereo MPI-RRIMs): Effective Visualization of High-Resolution Digital Elevation Models for Interpreting and Mapping Small Tectonic Geomorphic Features, Bulletin of the Seismological Society of America 109 (1), 2019, 99-109.; STEREO MPI-RRIM Calculators. en http://www.earth.s.chibau.ac.jp/webuser/kaneda $/ 5 \mathrm{mrrim} / \mathrm{mrrim} . \mathrm{html}$
} 

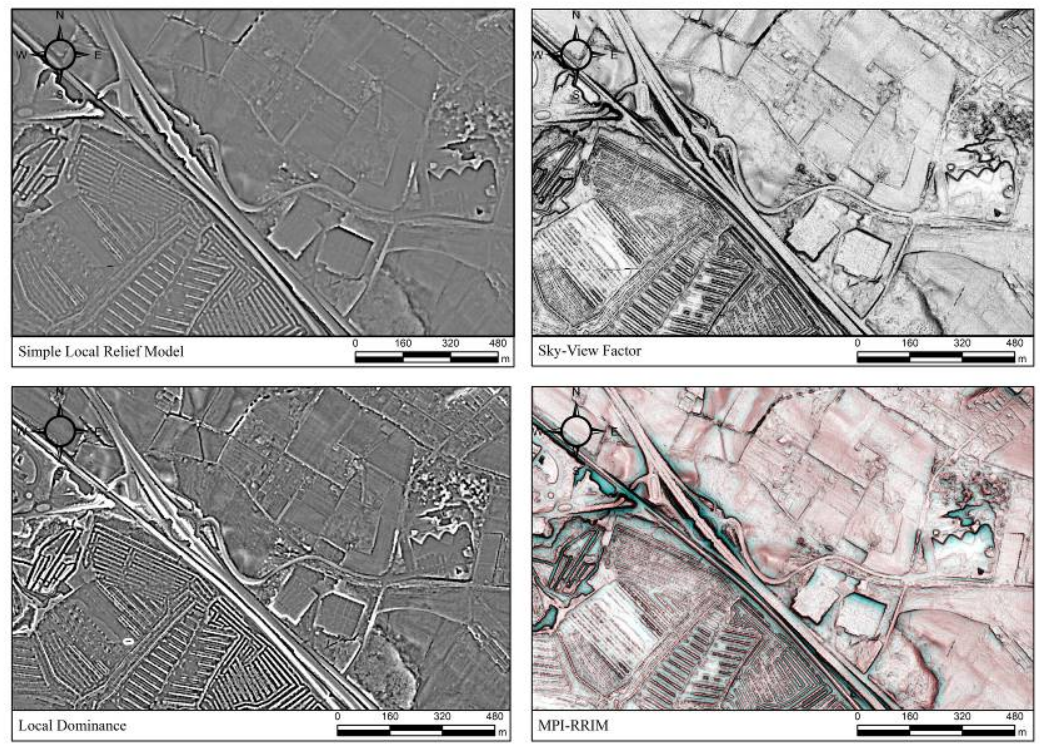

Fig. 5: Distintas visualizaciones del MDT

En la figura 5, se aprecian las cuatro visualizaciones descritas para el entorno del asentamiento de Puente Melchor. Pueden observarse las diferencias entre los modelos y, aunque a esa escala y debido a las propias características del área, podría parecer que no ofrecen significantes resultados, para lo que aquí compete, cuando se pone en relación con otros elementos de carácter histórico-arqueológicos y se aplica sobre una zona más reducida, se detectan elementos en el terreno que no parecen naturales. Esto se tratará más pormenorizadamente en el apartado de Resultados.

Isabel Rondán Sevilla, "El asentamiento de Puente Melchor (Puerto Real, Cádiz)", RIPARIA 6 (2020), 30-73. 


\section{Una aproximación al marco geográfico original del yacimiento.}

La búsqueda del marco geográfico original de Puente Melchor es importante a la hora de plantear posibles elementos de comunicación dentro del entorno o, por ejemplo, para ayudar a definir la funcionalidad de algunas de las áreas intervenidas. Pero resulta una tarea tan importante como compleja: la "restitución" histórica de los entornos costeros, como el de Puente Melchor, es difícil por todas las variables que habría que tener en cuenta, especialmente la línea de costa, sobre todo en la bahía.

Con los modelos del terreno trabajados, las investigaciones sobre la modificación del eustatismo en la zona, los datos digitales de referencia, cartografía histórica y el uso de determinadas herramientas GIS se plantea un ejemplo de cómo podría haber sido ese marco donde encajar el resto de elementos trabajados en el presente artículo, aceptando todas sus limitaciones y complejidades.

Los estudios geoarqueológicos en ambientes costeros establecen al menos cuatro procesos que interactúan provocando cambios: oscilaciones del mar como consecuencia de fenómenos tecnoeustáticos; cambios climáticos; el efecto erosivo de procesos potentes de energía, como tsunamis; y la actividad antrópica ${ }^{32}$.

En cuanto a la línea de costa y su variación desde época romana existen algunos trabajos que arrojan datos de gran ayuda ${ }^{33}$. El máximo transgresivo marino se alcanza en esta zona entre el 6.800 y el 6.000 B.P., esto dejó evidencias como cordones dunares o depósitos marinos colgados por encima del nivel del mar actual. La sedimentación arenosa litoral del saco interior de la

32 C. Alonso Villalobos, F.J. Gracia Prieto, J. Benavente GonzÁlez, Evolución histórica de la línea de costa en el sector meridional de la Bahía de Cádiz, Revista Atlántica-Mediterránea de Prehistoria y Arqueología Social, 13-37, 2009, 28. Universidad de Cádiz.

33 J. R. Vanney, L. Menanteau, Mapa fisiográfico del Litoral Atlántico de Andalucía 1:50.000, 1985. Junta de Andalucía. 
Bahía de Cádiz parece haber coincidido con el máximo flandriense. El proceso posterior que sufrió el nivel del mar favoreció la formación de flechas litorales en esta zona. Concretamente una de esas fases de progradación de las flechas se dio en época romana (hace 2050-1820 años) ${ }^{34}$, lo que además favoreció el desarrollo de ambientes estuarinos y marismas en la zona, posiblemente gracias al aporte de sedimentos arrastrados por los ríos como consecuencia, entre otros, por el incremento de la deforestación en época romana ${ }^{35}$.

Concretamente al sur del Barrio Jarana se ha descrito ese máximo flandriense como una terraza marina colgada, un depósito de 1,5$2 \mathrm{~m}$ de arenas medias con abundantes fragmentos de bivalvos, la base de este depósito la sitúan en torno a 2,5-3 m del nivel del mar y la parte superior estaría compuesta por arenas más finas. Durante el máximo transgresivo se desarrolla un periodo de estabilización con evidencias de micro-acantilados y algunas flechas litorales, favorecidas en época fenicia y romana por la actividad de deforestación. La evolución eustática posterior provoca la formación de un cuerpo arenoso de unos $3 \mathrm{~km}$ de longitud, aislado por marismas. En el entorno de Puente Melchor se detecta una terraza marina, formada por un depósito de playa donde abundan bioclastos, huellas de bioturbación y material cerámico romano. La base de esta playa se encuentra a $+0,76 \mathrm{~m}$ del nivel medio actual de pleamar viva. En términos generales algunos investigadores concluyen que esta época el nivel del mar se encontraba en torno a $0,5 \mathrm{~m}$ por encima del nivel actual ${ }^{36}$.

El resto de datos para elaborar ese modelo que se han tenido en cuenta son, por un lado, la línea de costa digitalizada del mapa de

34 C. Zazo, J.L. Goy, J. Lario, P.G. Silva, Littoral zone ad rapid climatic changes during the last 20.000 years. The Iberia case, Zeitschrift für Geomorphologie N.F, Suppl. Bd. $102,119-134$.

35 C. Alonso Villalobos ET AL., Evolución histórica de la línea de costa..., 17-20.

36 F.J. Gracia, C. Alonso, M. Gallardo, F. Giles, J. Benavente, F. López, Evolución eustática postflandriense en las marismas del Sur de la Bahía de Cádiz, Geogaceta 27, 2000, 71-74.

"El asentamiento de Puente Melchor (Puerto Real, Cádiz): integración de..." 
1789 del Puerto de Cádiz, ya citado, los puntos tomados con GPS en el entorno, y otra información vectorial como las láminas de aguas para el caso de las marismas o las curvas de nivel.

La idea planteada es obtener un modelo que conjugue el MDT y los datos de paleopaisaje. A partir de la línea de costa actual (IGN) y la digitalizada del plano de 1789, y a través del software Global Mapper, se ha subido el nivel del mar según los datos arrojados en los estudios geoarqueológicos. El principal escollo técnico para aplicar esta metodología es la enorme área de salinas existente desde época contemporánea. La morfología de las salinas, esteros, corredores y zonas de cristalización, con tantos cambios microtopográficos cercanos, arrojaría un resultado poco realista. De tal manera que se ha rasterizado mediante interpolación toda esa área. Se han dado puntos a las zonas menos artificiales de las salinas y se han tomados puntos también fuera de esa área. Para ello se ha digitalizado una cartografía de las salinas $^{37}$. El resultado final es la integración de los datos geoarqueológicos, la "nueva" línea de costa obtenida aplicando los datos anteriores teniendo en cuenta una zona más suavizada en lo que al espacio salinero se refiere y la unión de este resultado con el MDT ya elaborado. La figura 6 resume gráficamente lo detallado en este apartado. En la figura 6.1 se aprecia el mapa del Brigadier D. Vicente Tofiño de 1789 georreferenciado sobre la ortofoto del vuelo Interministerial. Como se ha hecho referencia, esta cartografía histórica ha sido utilizada para poder entender un entorno menos antropizado y comprender cómo era la topografía, sobre todo por la línea de costa.

37 J. M. Barragán Muñoz (COORD.), Estudios para la Ordenación, Planificación y Gestión de las zonas búmedas de la Bahía de Cádiz, 1996, Anexo C, Oikos-Tau y Universidad de Cádiz. Barcelona. 


\section{RONDÁN SEVILLA}

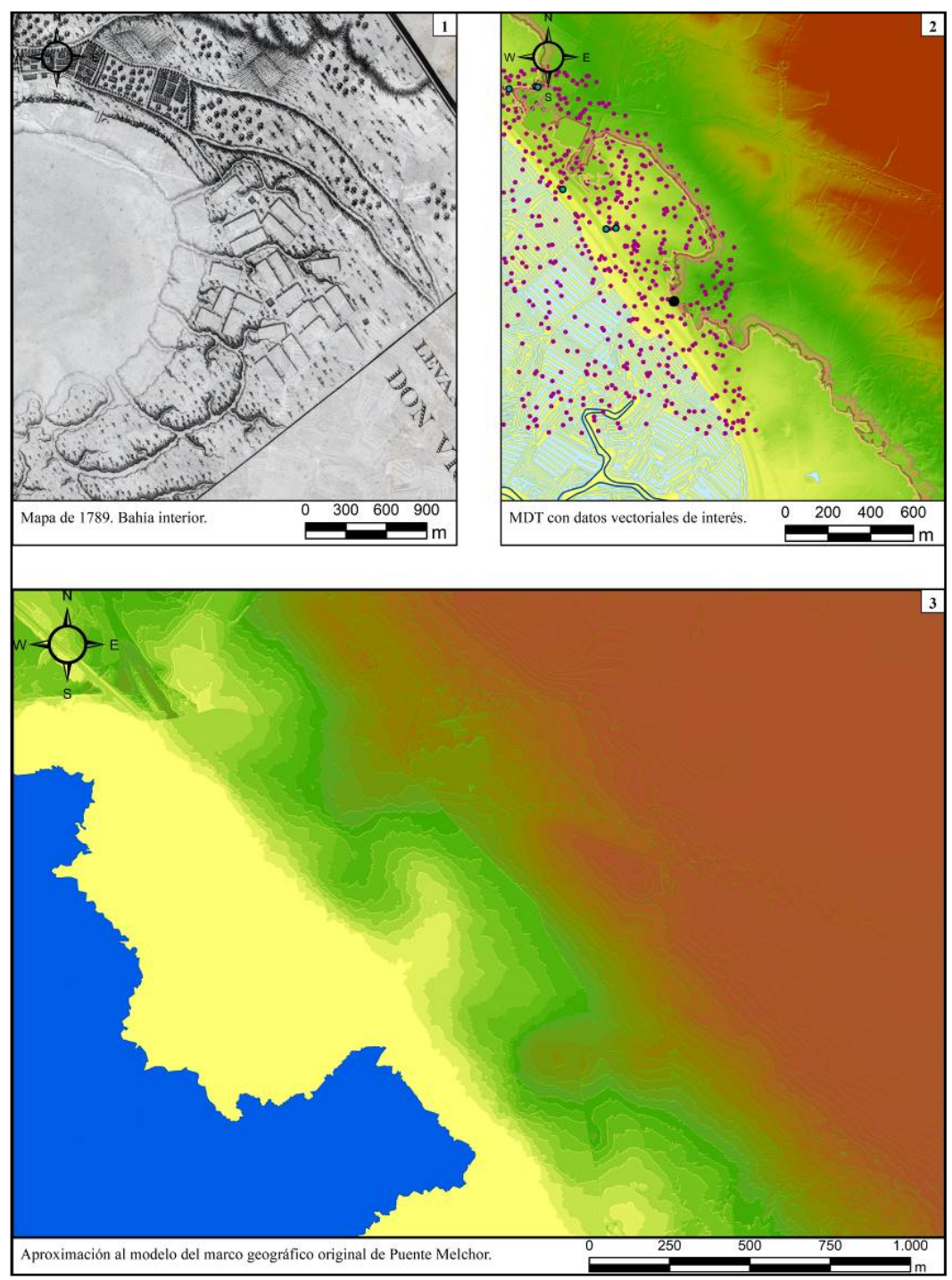

Fig. 6. Flujo de trabajo para crear el modelo de aproximación al contexto geográfico original.

“El asentamiento de Puente Melchor (Puerto Real, Cádiz): integración de..." 
En cuanto a la figura 6.2. refleja la mayor parte de los datos con los que se ha trabajado, además del anterior, hasta llegar a la aproximación de un modelo geográfico original (figura 6.3.). El punto señalado en el MDT corresponde con el acantilado flandriense, tomado con GPS en una zona donde se aprecia claramente. También se han seleccionado las curvas de nivel en torno a ese punto (de 9 a 11,5 m) que parecen revelar datos interesantes sobre la configuración de la paleotopografía. Y, finalmente, se han digitalizado las láminas de agua correspondiente a las marismas y salinas, los 1000 puntos utilizados para la interpolación y rasterizado de la zona de salinas.

\section{Resultados. Interacción de la documentación generada y las intervenciones arqueológicas.}

En este punto se detallarán algunas anomalías detectadas a través de la metodología ya desarrollada, se pondrán en común distintas visualizaciones y las intervenciones arqueológicas digitalizadas.

En el caso del área en torno a la intervención arqueológica desarrollada en 1996 y 2007, ya se mostraron algunas anomalías a través de distintas visualizaciones de ortofotografías históricas (fig. 3). En la figura 7 (infra) se exponen tres imágenes que tienen como base la ortofoto del vuelo Interministerial. En la imagen 1 simplemente se ve la ortofoto de esa zona. En la imagen 2 se sobreponen a la anterior la digitalización de las intervenciones arqueológicas de 1994 y la de 2007, ya se puede apreciar cómo coinciden parte de las alteraciones lineales de la fotografía con las estructuras, algo evidentemente normal. Pero conjugando ambas, es posible prolongar parte de esos elementos hacia zonas no excavadas, así como apreciar otros detalles. En la imagen 3, por tanto, se señala mediante un recuadro verde la continuación del acueducto del siglo XVIII y en rojo un tramo más amplio de la calzada romana, excavados en parte. En el caso del acueducto es detectable en esta ortofoto y en otras en un amplio espacio del entorno de Puente Melchor, y estas visualizaciones han sido importantes para no confundirlo con otros posibles elementos arqueológicos con características morfológicas semejantes. 


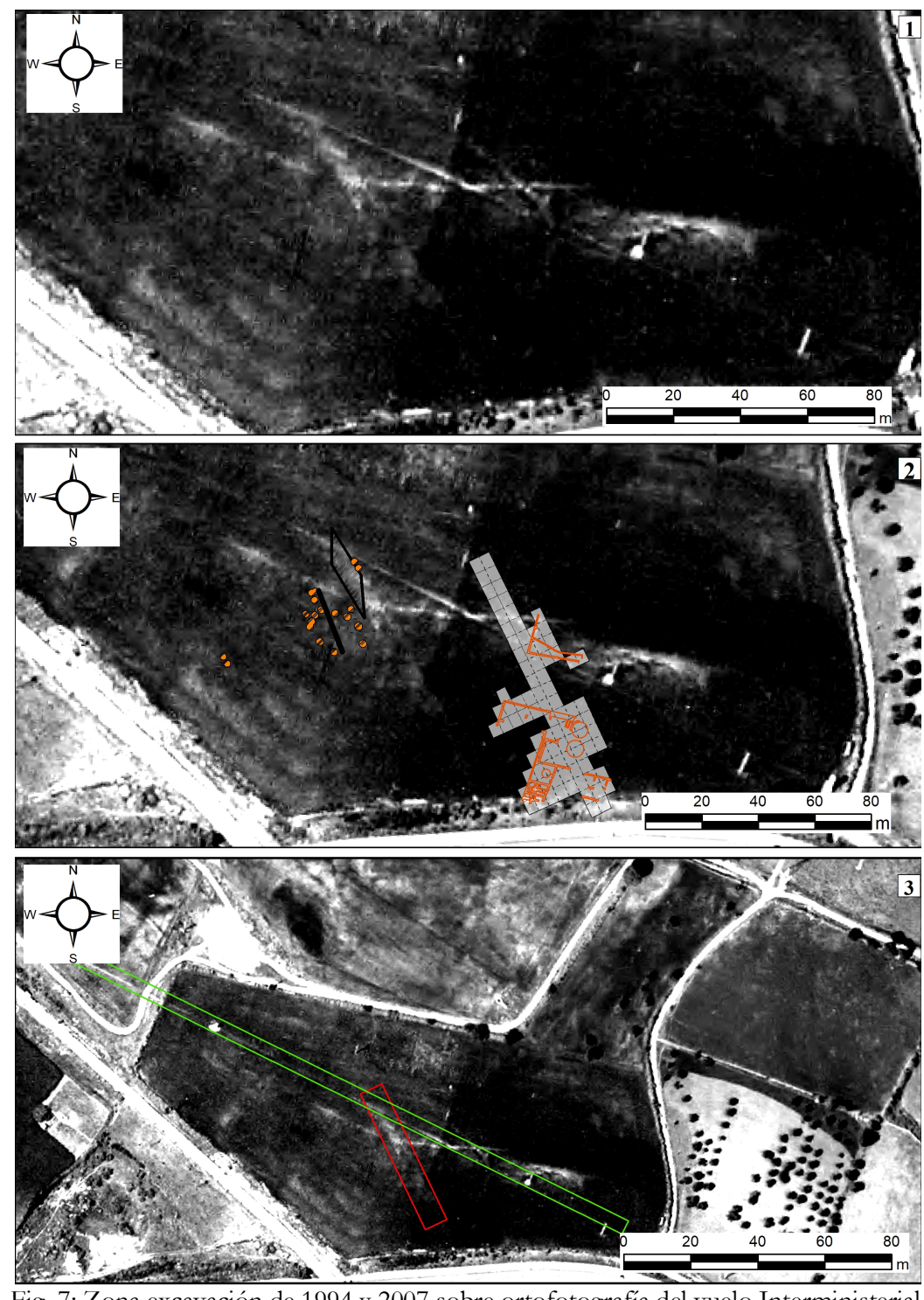

Fig. 7: Zona excavación de 1994 y 2007 sobre ortofotografía del vuelo Interministerial.

"El asentamiento de Puente Melchor (Puerto Real, Cádiz): integración de..." 
La calzada es de enorme interés intentar detectarla en otro tramo, pero se vuelve complicada su detección por el intenso intervencionismo sobre el espacio. Este elemento tiene una longitud de unos $80 \mathrm{~m}$ y un ancho de $8 \mathrm{~m}$ aproximadamente, al menos en esta visualización.

En la zona de la intervención arqueológica de 1996 caben destacar al menos dos elementos detectados a través de algunas de estas visualizaciones. Concretamente una continuación lineal de unos $20 \mathrm{~m}$ al suroeste de la excavación desarrollada junto a la rotonda del Hospital de Puerto Real, donde entre otros elementos aparecieron dos estructuras fornáceas. Esta solo se aprecia en la ortofoto del vuelo Interministerial, en las ortofotos más actuales esa zona está ocupada por la A-4 (fig. 8.1.). Además, en la finca al Este de esa intervención (polígono 48, parcela 96) se aprecian al menos dos conjuntos destacables que difieren con su entorno, aun mejor se observan en una de las visualizaciones del MDT, MPI-RRIM (fig. 8.2.). Lo interpretamos como espacios donde sobre la topografía natural se han generado vertidos o testares propios de una zona artesanal como es esta.

El análisis a través de esta metodología en torno a la zona donde se excavó el edificio villático, a un kilómetro al sureste del conjunto anteriormente descrito, es de enorme importancia para intentar poner en relación las distintas intervenciones. A priori la búsqueda y posible detección de otros tramos de la calzada tiene sentido en relación con este edificio. Si se toma como base el modelo que se ha planteado como una posible aproximación al entorno geográfico original, se detectan algunas características interesantes que puede ponerse en relación con alteraciones que cabrían ser interpretadas como parte de la calzada romana. 

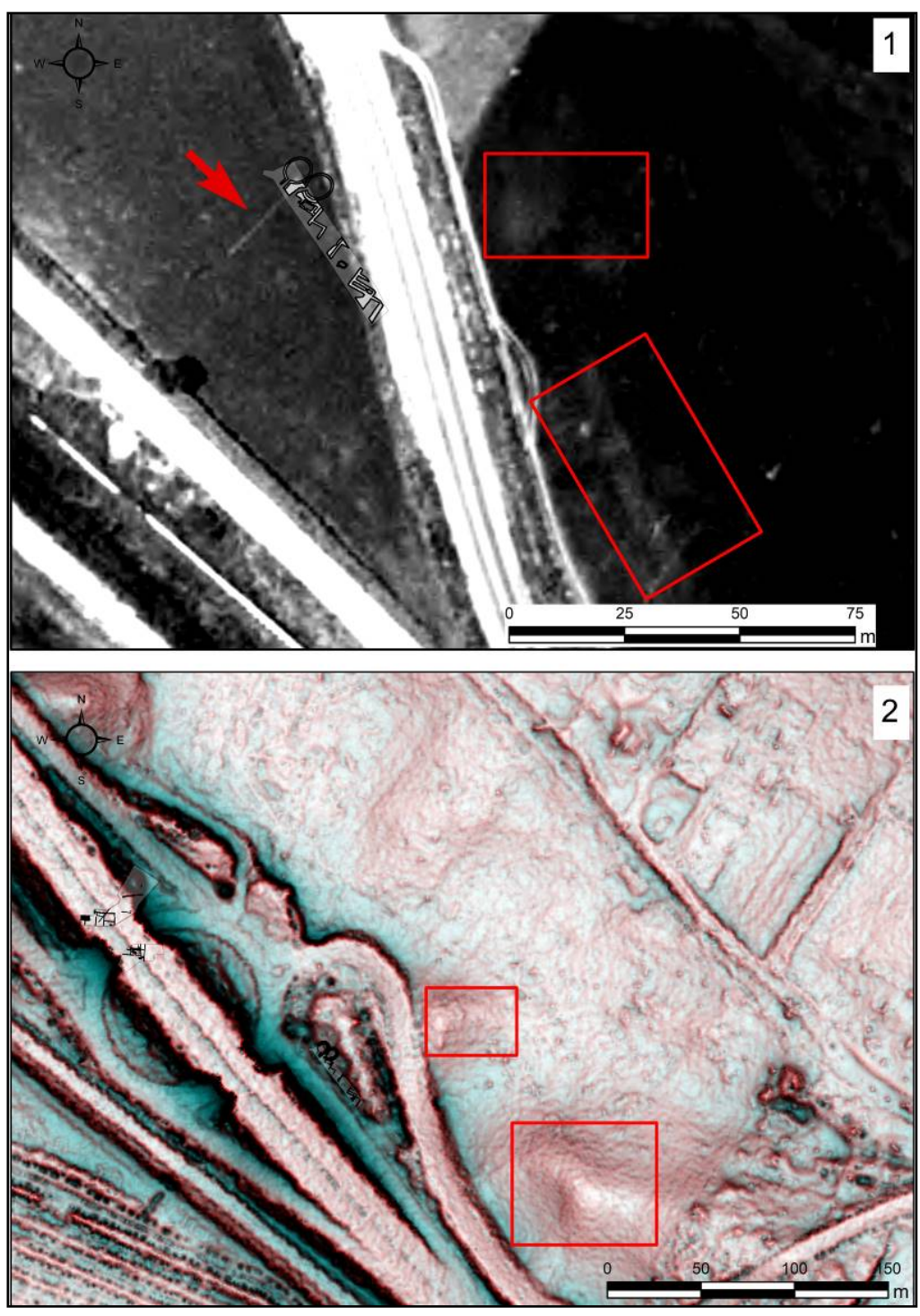

Fig. 8: Anomalías destacadas en torno a la intervención de 1996.

"El asentamiento de Puente Melchor (Puerto Real, Cádiz): integración de..." 
En la figura 9 se exponen algunas de esas ideas. Al norte de la intervención desarrollada en 2004, a unos 200 m aproximadamente, se detecta un elemento cuya morfología parece coincidir con la continuación de la calzada excavada en 2007 y que se apreciaba de manera clara en la ortofoto tratada del vuelo Interministerial (fig. 3.1. y 3.1'.). Es una zona con tendidos eléctricos, pero se compara con ortofotos históricas y de los últimos años y parece no coincidir con parte de los elementos actuales. Las visualizaciones donde se ha detectado son la MPIRRIM y Simple Local Relief Model (fig. 9.1. y 9.2, respectivamente). $\mathrm{Si}$ se ponen algunos elementos sobre el modelo planteado, el edificio excavado en 2004 queda a unos $150 \mathrm{~m}$ de distancia del supuesto nivel del mar del momento, lo que facilitaría la comunicación marítima por esta vía. Pero es importante señalar llegados a esto punto que muy probablemente la zona costera estuviese ocupada por marismas y antiguas salinas, como parecen arrojar los datos geoarqueológicos. Igualmente interesante es la conformación topográfica en forma de ensenada que se encuentra en esa misma zona. Se corresponde con la finca con referencia catastral polígono 45, parcela 2. Esta no parece excesivamente intervenida, si se analiza a través de ortofotografías históricas, se mantiene con pocos cambios topográficos a excepción de su esquina suroeste, donde existió una cantera hoy rellena. Parecen guardar coherencia espacial dentro del modelo los puntos tomados sobre el acantilado flandriense y otros donde hay materiales que podría formar parte de la construcción de dicha calzada romana. 

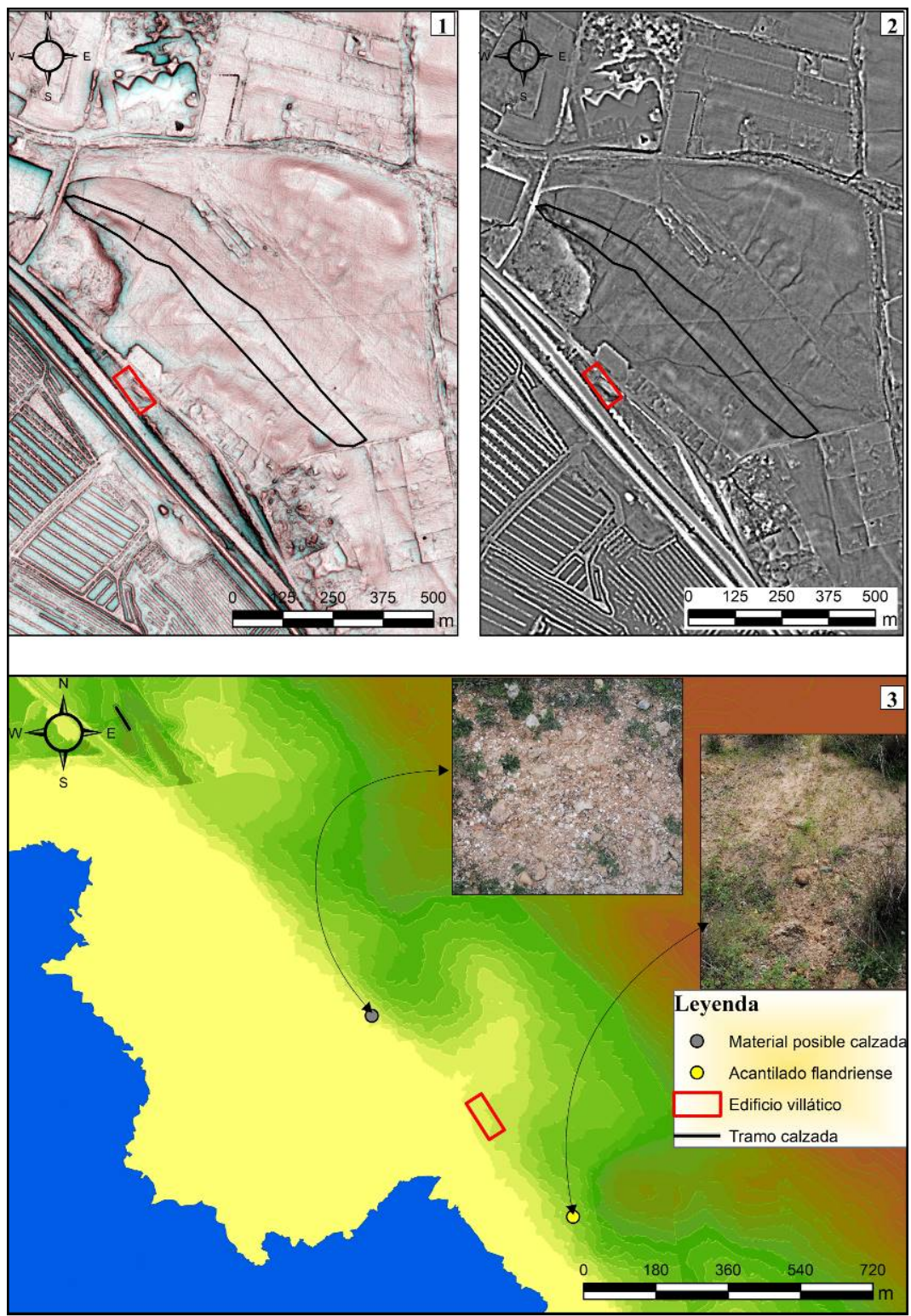

Fig. 9. Posible detección de la calzada y puesta en relación con otros elementos.

"El asentamiento de Puente Melchor (Puerto Real, Cádiz): integración de..." 


\section{Conclusiones. Hacia la creación de protocolos de actuación con metodologías no invasivas combinadas.}

El uso de la teledetección y otras herramientas no invasivas está mostrando en los últimos años un enorme potencial en la investigación histórico-arqueológica: la capacidad de integración de los productos generados por estas técnicas con los de la excavación arqueológica es una de sus principales ventajas. En el caso de áreas fuertemente antropizadas, donde la intervención arqueológica tradicional se vuelve muy compleja, aún cobra mayor sentido. Además del carácter finito del registro de la excavación arqueológica frente al no destructivo de este tipo de herramientas ${ }^{38}$.

Las dificultades que presentan asentamientos como el de Puente Melchor como su contexto geográfico litoral, el desarrollo de intervenciones de urgencias aisladas o la reestructuración viaria desarrollada en los últimos años, pueden verse reducidas con la aplicación de estas y otras metodologías del mismo tipo. La capacidad de las técnicas empleadas, junto con la información arqueológica y el análisis de las fuentes clásicas, parece mostrarse como una metodología factible para responder preguntas de carácter histórico.

La georreferenciación de algunas de las intervenciones arqueológicas integradas en un mismo plano ya aporta información relevante: la orientación de las estructuras no coincide en todas ellas, la cronología de uso de las mismas difiere como ya había sido estudiado en algunos de los trabajos citados. Pero es importante para entender la organización espacial del asentamiento donde la calzada debe tener especial protagonismo.

\footnotetext{
38 V. Mayoral Herrera, La integración de métodos no destructivos para el análisis de zonas arqueológicas. Balance de una experiencia transfronteriza y multidisciplinar, $L a$ Revalorización de zonas arqueológicas mediante técnicas no destructiva, Anejos de AEspA, LXXV, 2016, 11-14 Consejo Superior de Investigaciones Científicas, Mérida.
} 
Mientras que el tramo de calzada excavada, así como su continuación detectada en algunas visualizaciones, presenta una orientación NW-SE, al igual que el edificio excavado en 2004, las intervenciones de 1994, 1996 y 2008 tienen la orientación opuesta. La calzada sigue uno de los ejes urbanísticos canónicos y a este se ajusta también el principal edificio excavado en Puente Melchor, esto no puede ser casual. Además, el elemento detectado en las diferentes visualizaciones del MDT (fig. 9.1. y 9.2.) y susceptible de ser interpretado como otro posible tramo de la misma sigue esa misma orientación y con un ancho similar al descrito para el tramo excavado. Las dificultades por localizar en toda esta aérea el tramo de la via Augusta hacia Gades están claras por las características intrínsecas del territorio, aunque atendiendo a las fuentes clásicas (Itinerario de Antonio o Anónimo de Rávena) y al registro arqueológico se extraen algunas conclusiones. Por otro lado, las características morfométricas del tramo excavado y del detectado en algunas visualizaciones también coincide con las descripciones de este tipo de elemento urbanístico ${ }^{39}$.

Teniendo en cuenta lo anterior, a la calzada le acompaña una serie de infraestructura que en algún caso podría ser relacionada con alguno de los elementos detectados o excavados. Es el caso de las mansiones, stationes o mutationes, edificios de refugio, asilo y postas para los viajeros que se encuentran en torno al viario romano. Las mansiones estarían situadas cada 30 o 40 millas $^{40}$. Mientras que las stationes y mutationes se encontrarían en distancias inferiores, las primeras en torno a la media jornada de viaje y las segundas cada 5 ó 6 millas para el relevo de caballos de mensajeros públicos ${ }^{41}$. Las características de las mansiones a veces podrían ser confundidas con edificios villáticos rurales. Para el caso que aquí

39 V. PONTE, Régimen jurídico de las vías romanas, Las técnicas y las construcciones de la Ingeniería Romana, V Congreso de las obras Públicas Romanas, 2010, 81-83.

40 Plin. N.H. 6.102.

41 V. PonTE, Régimen jurídico de las vías romanas..., 86.

"El asentamiento de Puente Melchor (Puerto Real, Cádiz): integración de..." 
compete, el lugar en el que se encuentra el supuesto complejo villático, una zona de paso importante donde la salida a la importante producción alfarera documentada en Puente Melchor tendría sentido con una mansio relativamente compleja. Asignar el edificio excavado en 2004 con alguna de las mansiones descritas en el Itinerario de Antonino o en los Vasos de Vicarello como Ad Portum o Ad Pontem podría ser una hipótesis de partida, no definitiva, con los datos que se tienen y teniendo en cuenta la complejidad del territorio ${ }^{42}$. En este sentido, la detección de la calzada romana junto a ese edificio es importante para plantear otras posibiliades funcionales. Los usos de ese acusativo en el Itinerario han definido las mansiones según diversos criterios, en este caso Monumenta y Geográficos. Y el número junto al nombre señala la localización en millas de la misma, entendido como dónde se encuentra en relación a la anterior o en un sentido dinámico, a partir de la cual se inicia el recorrido que corresponde a esa numeración ${ }^{43}$.

Por otro lado, a la producción alfarera atestiguada por la arqueología y por algunos de los resultados presentados debería ir acompañada de una red de comunicación. La calzada es un elemento claro en este sentido, pero la aproximación al marco geográfico original del asentamiento planteado también podría aportar datos interesantes. La línea de costa de esta época, así como los caños que debían de existir, colmatados en la actualidad, pero que parecen dejar testigos en la conformación del espacio marismeño y salinero, hace factible la posibilidad de que este asentamiento, más concretamente en la actual localización del Barrio Jarana, existiese una pequeña ensenada o espacio portuario (fig. 6 y 9.3.). Esto facilitaría y le daría sentido a la producción que se atribuye a Puente Melchor. Además, el ambiente marismeño

42 L. G. Lagóstena Barrios, F. De B. Zuleta Alejandro, Gades y su acueducto: una revisión, en L.G. Lagóstena BArrios, F. DE B. Zuleta Alejandro (COORDS.) La captación, los usos y la administración del agua en Baetica: estudios sobre el abastecimiento bidrico en comunidades cívicas del Conventus Gaditanus, 2009, 124-126.

43 J.M. Roldán Hervás, Sobre los Acusativos con $<<\mathrm{ad}\rangle>$ en el Itinerario de Antonino, Zephyrus, XVII, 1966, 110-114. 
que posiblemente existiese en ese momento, como señalan estudios geoarqueológicos, evidentemente no con la extensión actual, posibilita que los implantes salineros romanos formasen parte del paisaje guardando relación, por tanto, con la actividad de Puente Melchor ${ }^{44}$.

La dificultad de identificar estos vestigios arqueológicos, debido a las características propias de los ambientes litorales, unido a que no ha gozado de atención protagonista en la investigación, hace que sea un elemento complejo de analizar y detectar ${ }^{45}$. La posible zona portuaria tendría sentido dentro del modelo del terreno planteado según las condiciones geomorfológicas ${ }^{46}$, pero sin duda se necesitan más datos para poder plantear esta idea como un estudio exhaustivo de las modificaciones temporales del área, o la realización de análisis geoarqueológicos mediante perforaciones.

Para finalizar los productos generados a partir de esta metodología no tiene su principal potencial en los datos que arrojan por sí mismo sino la capacidad de complementarse, integrarse y enriquecer la información arqueológica o las fuentes clásicas. En el caso de asentamientos como Puente Melchor con las problemáticas comentadas reiteradamente tiene un sentido aún más claro. De tal manera que de este tipo de aportaciones se pueden extraer protocolos de actuación que se utilicen como base para ser aplicados en contextos arqueológicos similares. Ya no sólo para complementar el registro arqueológico y literario previo, sino para plantear otras posibles actuaciones mediante metodología no invasiva que sigan arrojando datos de interés

44 L.G. Lagóstena Barrios, J.L. Cañizar Palacios, Salinae Maritimae en Baetica: condiciones ambientales y consideración jurídica, Riparia dans l'Empire Romain: pour la définition du concept. BAR International Series 2066, 29-31 Octobre 2009, 2010, 68-71.

45 L.G. LAGÓSTENA BARRIOS, Aproximación a la problemática y el paisaje de las salinas de Gades, Homenaje al Profesor Cristóbal González Román, Granada (e.p.)

46 M. Vitruvio Polión, Capítulo doce, Los puertos y astilleros, Los Diez Libros de Arquitectura, traducción de J. L. Oliver Domingo, 1997, 138-140. Alianza Forma.

“El asentamiento de Puente Melchor (Puerto Real, Cádiz): integración de..." 
histórico-arqueológico. Para Puente Melchor, la teledetección aérea mediante fotogrametría y otros análisis y el tratamiento de las imágenes obtenidas parecen haber mostrado un resultado positivo, pero a este se podrían sumar el empleo de otras técnicas no invasivas una vez que hemos analizado los primeros resultados. En determinadas zonas el desarrollo de prospecciones geofísicas tendría ahora mucho sentido. El uso de técnicas GPR (Ground Penetrating Radar) para continuar con la detección de los tramos de calzada, así como comprobar las hipótesis planteadas previamente en cuanto a su localización, es la aplicación más clara $^{47}$. Pero, además, la prospección mediante magnetómetro en un entorno donde la existencia de hornos y testares es evidente aportaría una mayor información al registro que hasta ahora se tiene (fig. 10).

P. Soto Cañamares, Métodos geofísicos en el marco del Proyecto Riteca II. Trabajos realizados por el Instituto de Arqueología de Mérida (CSIC-GOBEX), La Revalorización de zonas arqueologías mediante técnicas no destructiva, Anejos de AEspA, LXXV, 2016, 79-98. Consejo Superior de Investigaciones Científicas, Mérida. 
RIPARIA VOL. 6 (2020)

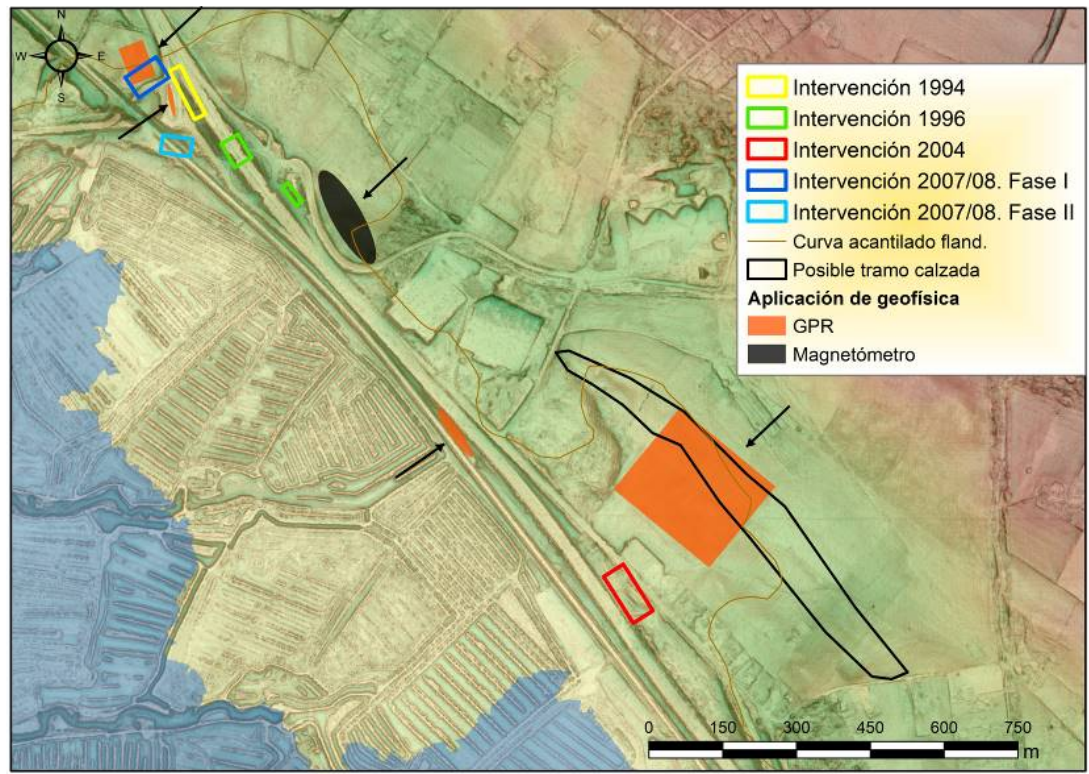

Fig. 10: Digitalización gráfica de las conclusiones sobre MPI-RRIM y MDT de aproximación geográfica con la subida del mar. Áreas propuestas para aplicación geofísica.

Isabel Rondán Sevilla, "El asentamiento de Puente Melchor (Puerto Real, Cádiz)”, RIPARIA 6 (2020), 30-73. 


\section{Bibliografía}

C. Alonso Villalobos, F.J. Gracia Prieto, J. Benavente GONZÁLEZ, Evolución histórica de la línea de costa en el sector meridional de la Bahía de Cádiz, Revista Atlántica-Mediterránea de Prehistoria y Arqueología Social, 11, 2009, 13-37. Universidad de Cádiz.

J.M. BARRAgÁN MUÑOZ (COORD.), Estudios para la Ordenación, Planificación y Gestión de las zonas húmedas de la Babia de Cádir, 1996, OikosTau y Universidad de Cádiz. Barcelona.

Cartografía Histórica de la Bahía De Cádiz, Mapas y Planos extraídos de la Biblioteca Nacional de España. Consultado en https://milan2.es/PortalSanFernando/SanFernandoCartografia BNE. html

C. CHACón MOHEDANO, Nuevas estructuras arqueológicas documentadas en el yacimiento de Puente Melchor, Puerto Real, Cádiz, Mainake XXXIV, 2013, 77-97.

G. DOUGHeRTY, Digital Image Processing for Medical Applications, Cambridge University Press, Cambridge.

A. Durán Macías, El mosaico de Baco (Puente Melchor, Cádiz), arqueología arqueometría y musealización, Revista de Investigación y Letras, No 1, 2017, Universidad de Cádiz, 114-173.

L. Girón AnguiOzAR, Las cerámicas comunes del alfar romano de Puente Melchor (Puerto Real, Cádiz): un ensayo de clasificación de las formas abiertas, Herakleion, 3, 2010, 105-162.

F. J. Gracia, C. Alonso, M. Gallardo, F. Giles, J. Benavente, F. LÓPEZ, Evolución eustática postflandriense en las marismas del Sur de la Bahía de Cádiz. Geogaceta 27, 2000, 71-74.

R. HESSE, LiDAR-derived Local Relief Models: a new tool for archaeological prospection, Archaeological Prospection, 17 (2), 2010, 67-72.

INSTITUTO DE ESTADÍSTICA Y CARTOGRAFÍA DE ANDALUCÍA. Base Cartográfica de Andalucía 1:10.000 - BCA10. Recuperado de

Isabel Rondán Sevilla, "El asentamiento de Puente Melchor (Puerto Real, Cádiz)”, RIPARLA 6 (2020), 30-73. 
https://www.juntadeandalucia.es/institutodeestadisticaycartografia/pro dCartografia/bc/bca.htm

INSTITUTO GEOGRÁFICO NACIONAL, LiDAR 1ª Cobertura 2008-2015, Centro de Descarga. Recuperado en http://centrodedescargas.cnig.es/CentroDescargas/catalogo.do?Serie= CAANE

Instituto Geográfico NACiOnAl, Línea de Costa Actual, Centro de descarga. Recuperado en http://centrodedescargas.cnig.es/CentroDescargas/catalogo.do?Serie= CAANE

INSTITUTO GEOGRÁFICO NACIONAL, Ortofotos e imágenes satélites, Centro de descarga. Recuperado en http://centrodedescargas.cnig.es/CentroDescargas/catalogo.do?Serie= CAANE\#

H. KANEDA, T. CHIBA, Stereopaired Morphometric Protection Index Red Relief Image Maps (Stereo MPI-RRIMs): Effective Visualization of High-Resolution Digital Elevation Models for Interpreting and Mapping Small Tectonic Geomorphic Features, Bulletin of the Seismological Society of America 109 (1), 2019, 99-109.

Z. KOKALJ, K. OŠTIR, K. ZAKSEK, Visualization of lidar dereived relief models, en R.S Opitz y D. C. Cowley (eds.), Interpreting Archaeological Topography: Airborne laser scanning, 3D data and ground observation, 2016, 100-114. Oxbow Books.

Z. Kokalj, K. ZakšeK, K. OŠtir, P. Pehani, K. Čotar, Relief Visualization Tollbox, ver. 1.3 Manual, 2016.

L.G. LAgÓSTENA BARRIOS, Aproximación a la problemática y el paisaje de las salinas de Gades, Homenaje al Profesor Cristóbal González. Román, Granada (e.p.).

L.G. LAGÓSTENA, D. BERNAL (eds.), Figlinae Baeticae: Talleres alfareros y producciones cerámicas en la Bética romana (ss. II a.C.-VII d.C): Actas del Congreso Internacional. BAR International Series, 1266, Cádiz, 12-14 de noviembre de 2003, 2, 2004, 473-488.

L.G. Lagóstena Barrios, J.L. CañIzar Palacios, Salinae Maritimae en Baetica: condiciones ambientales y consideración jurídica, Riparia dans

“El asentamiento de Puente Melchor (Puerto Real, Cádiz): integración de..." 
l'Empire Romain: pour la définition du concept. BAR International Series 2066, 29-31 Octobre 2009, 2010, 68-84.

L.G. LAgÓstena BArRios, F. DE B. ZuletA AlejANDRO, Gades y su acueducto: una revisión, en L.G. LAGÓSTENA BARRIOS, F. DE B. ZULETA ALEJANDRO (COORDS.) La captación, los usos y la administración del agua en Baetica: estudios sobre el abastecimiento bidrico en comunidades cívicas del Conventus Gaditanus, 2009, 117-172.

M.L. LAVAdO FloridO, El complejo industrial de Puente Melchor: el centro productor, la organización del espacio y su área de influencia, en

M.L. LAVADO FLORIDO, Memoria final de la intervención arqueológica llevada a cabo en proyecto de la duplicación de la carretera N-IV. Tramo final: variante Puerto Real-Tres Caminos del P.K. 671,8. Cádiz, Anuario de Arqueología de Andalucia, 2004, 2, Consejería de Cultura, Sevilla, 99-144.

V. MAYORAL HERRERA, Arqueología aérea y teledetección en el suroeste peninsular. La experiencia del Poryecto Riteca II, La Revalorización de zonas arqueologías mediante técnicas no destructiva, Anejos de AEspA, LXXV, 2016b, 24-40. Consejo Superior de Investigaciones Científicas, Mérida.

V. MAYORAL HERRERA, La integración de métodos no destructivos para el análisis de zonas arqueológicas. Balance de una experiencia transfronteriza y multidisciplinar, La Revalorización de zonas arqueologías mediante técnicas no destructiva, Anejos de AEspA, LXXV, 2016, 11-18. Consejo Superior de Investigaciones Científicas, Mérida.

M.L. Millán SAlgadO, M.C. Gómez BuenO, El mosaico de la villa romana de Puente Melchor: estudio histórico-artístico y tratamiento de conservación, ROMVLA, 11, 2012, 115-136.

J. Olmo MARTín, Arqueología Aérea en Castilla y León, La Revalorización de zonas arqueologías mediante técnicas no destructiva, Anejos de AEspA, LXXV, 2016, 197-210 Consejo Superior de Investigaciones Científicas, Mérida.

C. PEMÁn PEMARTín, Alfares y embarcaderos romanos en la provincia de Cádiz, A.E.A. vol. 32, nº 99, 1959, 169-173. 
V. PONTE, Régimen Jurídico de las Vías Romanas, Las técnicas y las construcciones de la Ingeniería Romana, $V$ Congreso de las obras Públicas Romanas, 2010, 75-118.

REDIAM, Ortofoto Digital Pancromática de Andalucía 1956-57, Servicio WMS. Recuperado en http://www.juntadeandalucia.es/medioambiente/mapwms/REDIAM Ortofoto Andalucia 1956?

J.M. ROLDÁn HERvÁs, Sobre los Acusativos con $<<\mathrm{ad}\rangle>$ en el Itinerario de Antonino Zephyrus, XVII, 1966, 109-119.

P. Soto Cañamares, Métodos geofísicos en el marco del Proyecto Riteca II. Trabajos realizados por el Instituto de Arqueología de Mérida (CSIC-GOBEX), La Revalorización de zonas arqueologías mediante técnicas no destructiva, Anejos de AEspA, LXXV, 2016, 79-98. Consejo Superior de Investigaciones Científicas, Mérida.

STEREO MPI-RRIM CALCULATORS. Recuperado en http://www.earth.s.chiba-

u.ac.jp/webuser $/$ kaneda $/ 5 \mathrm{mrrim} / \mathrm{mrrim} . \mathrm{html}$

M. SOMRAK, S. DŽEROSKI, Ž. KOKALJ, Learning to Classify Structures in ALS-derived Visualizations of Ancient Maya Settlements with CNN, Remote sening 12, 2020, 1-20.

B. ŠTULAR, Ž. KOKALJ, K. OŠTIR, L. NUNINGER, Visualization of lidarderived relief models for detection of archaeological features, Journal of Archaeological Science 39, 2012, 3354-3360.

V. Tofiño De SAN Miguel, Brigadier de la Real Armada, Plano del Puerto de Cádiz [Mapa]. 1:30.000. Servicio de Biblioteca, Archivos Topográficos y Cartoteca del IGN.: Madrid, 1789: Depósito Hidrográfico.

J.R. VAnney, L. Menanteau, Mapa fisiográfico del Litoral Atlántico de Andalucía 1:50.000, 1985. Junta de Andalucía.

K. ZAKSEK, K. OŠTiR, Ž. KOKALJ, Sky-View Factor as a Relief Visualization Technique, Remote Sensing, 3, 2011, 398-415.

“El asentamiento de Puente Melchor (Puerto Real, Cádiz): integración de..." 
RIPARIA VOL. 6 (2020)

C. Zazo, J.L. Goy, J. LARIO, P.G. Silva, Littoral zone ad rapid climatic changes during the last 20.000 years. The Iberia case, Zeitschrift für Geomorphologie N.F, Suppl. Bd. 102, 119-134. 